\title{
The effect of prostaglandin induced labor and selected factors on the occurrence and extent of birth-canal injuries
}

\author{
Kacvinska A, Drab M, Totka A, Holoman K, Gabor M \\ 2nd Department of Gynaecology and Obstetrics, Medical Faculty of Comenius University, \\ Bratislava, Slovakia. akacvinska@gmail.com
}

\section{ABSTRACT}

OBJECTIVES: To determine the effect of labor induction using prostaglandin, gestation period and delivery type on the cause and extent of birth-canal injuries.

METHODS: A retrospective study based on the records of II. GPK UNB Ružinov. The total set $(n=1377)$ consisted of patients who went into labor in second half of the year 2014 at this clinic. The research used categorical data divided into groups of factors (induction, week of delivery, type of delivery) and birth injuries. Using the chi-square test and Fisher's test we evaluated individual statistical dependences. The results with the highest level of significance are expressed through contingency tests (Phi coefficient, contingency coefficient, Cramer's V). Finally, because of the highest level of significance we have done a cohort study to express the incidence of relationship between non-operative delivery per vaginam and 1st degree ruptura perieni.

RESULTS: Labor induction with prostaglandins has a positive impact on the cause and extent of birth-canal injuries, namely the increased risk of vaginal walls tearing and uterine ruptures. We confirmed that the induction of labor using PG carries a demonstrable risk of pregnancy termination by cesarean section $\left(p=6.17 \times 10^{-9}\right)$. Birth-canal injuries are also affected by the type of delivery. Non-operative vaginal delivery is a significant risk factor for first-degree perineal tear $(R R=25.5295 \% \mathrm{Cl} 10.58,61.60$, OR $=33.0695 \% \mathrm{Cl} 13.51,80.90)$. Significant risk factors for third-grade perineal tear during vaginal delivery are forceps $(p=0.005534) /$ vacuum extractor $(p=0.03554)$.

CONCLUSION: In a group of 1377 patients we have demonstrated that the labor induction with prostaglandins, gestation period and type of delivery significantly influence the occurrence and extent of birth-canal injuries (Tab. 3, Ref. 9). Text in PDF www.elis.sk.

KEY WORDS: labor induction, gestation period, type of delivery, birth-canal injuries

\section{Introduction}

Childbirth is a natural event the course of which is influenced by many factors. It is not just about the environment and conscientious preparation for delivery, but it is mainly about good planning and labor management. Determining the right time and type of delivery is crucial since it may influence potential damage to the mother or fetus during labor.

The obstetricians may intervene during childbirth in different ways. One of them is the labor induction with prostaglandin (PG). These substances have their indications and contraindications. If not respected, they can lead among other things to a major obstetric trauma. Hasty and imprudent labor induction increases the incidence of births by operations, particularly Caesarean section. $(1,9)$

The aim of the article was to find out answers to the following questions - does labor induction with PG have an impact on the occurrence and extent of birth-canal injuries; does the type of

2nd Department of Gynaecology and Obstetrics, Medical Faculty of Comenius University, Bratislava, Slovakia

Address for correspondence: A. Kacvinska, Ruzinovska 6, SK-826 06 Bratislava, Slovakia.

Phone: +421.904834788 delivery have an impact on the incidence of birth-canal injuries; does the due date have an impact on the type of delivery and the occurrence of birth-canal injuries?

\section{Materials and methods}

The basis for our research was a study of birth records recorded by 2nd Department of Gynaecology and Obstetrics of the University Hospital Bratislava - Ružinov. The records are from the second half of the year 2014 .

The total set consists of all births $(n=1377)$ that took place in that period of time. The research used categorical data the structure of which has been adjusted to fit the objective of the study. The study made use of factors affecting birth-canal injuries.

For the sake of statistics the factors were combined into groups of factors, in particular induction, week of delivery, type of delivery.

The first factor was the labor induction with prostaglandin E2. Patients $(n=1377)$ were divided into two groups - patients undergoing labor induction ( $\mathrm{n}=214)$ and patients not undergoing labor induction $(\mathrm{n}=1163)$.

Another factor for the occurrence of obstetric trauma is the gestation period. In this respect four groups of patients were cre- 
Tab. 1. Studied factors.

\begin{tabular}{|c|c|c|c|}
\hline Group of factors & Factor & Structure & Description \\
\hline \multirow{2}{*}{ Induction } & \multirow{2}{*}{ Induction } & yes & Labor induced with PGE2 \\
\hline & & no & Labor without PGE2 \\
\hline \multirow{4}{*}{ Week of delivery } & 38 week & & Delivery before and in 38th week \\
\hline & 39 week & & Delivery in 39 week \\
\hline & 40 week & & Delivery in 40 week \\
\hline & 41 and 42 week & & Delivery in 41 week and after \\
\hline \multirow{3}{*}{ Type of delivery } & OVDV & & Operative vaginal delivery per vacuumextractor \\
\hline & OFVD & & Operative vaginal delivery per forcipem \\
\hline & S.C & & Sectio caesarea \\
\hline \multirow{2}{*}{ Oxytocin } & \multirow{2}{*}{ Oxytocin } & yes & The use of oxytocin during labor \\
\hline & & no & Without oxytocin during labor \\
\hline
\end{tabular}

Tab. 2. Birth-canal injuries.

\begin{tabular}{lll}
\hline Injury & Structure & Description \\
\hline $\begin{array}{l}\text { Laessio labii minoris, majoris, laessio } \\
\text { paraurethralis }\end{array}$ & Yes & $\begin{array}{l}\text { Laessio labii minoris l sin / l dx / bilateralis } \\
\text { Laessio labii majoris l sin / l dx / bilateralis } \\
\text { Laessio paraurethralis l sin / l dx / bilateralis }\end{array}$ \\
\cline { 2 - 3 } Ruptura perinei & No & Ruptura perinei 1. grade (including fissura perinei) \\
\cline { 2 - 3 } Ruptura parietis vaginae & RP2 & Ruptura perinei 2. grade \\
\hline & RP2 & Ruptura perinei 3. grade \\
\cline { 2 - 3 } & Yes & \\
\cline { 2 - 3 } Ruptura cervicis & No & Ruptura cervicis ad No 3 \\
\cline { 2 - 3 } & RC9 & Ruptura cervicis ad No 9 \\
\hline Extent of injuries & RC3+9 & Ruptura cervicis bilaterale \\
\hline
\end{tabular}

ated - patients who have given birth in and before 38th week of pregnancy $(n=235)$, in 39th week $(n=290)$, in 40th week $(n=$ 495). The last group consisted of patients giving birth in / after 41st week of pregnancy ( $n=357)$.

The third factor is the type of delivery. This group includes 4 types of delivery - non-operative vaginal delivery (NOVD, $\mathrm{n}=$ 837), operative vaginal deliveries using vacuum extractor (OVDV, $\mathrm{n}=35$ ), operative forceps-assisted vaginal delivery (OFVD, $\mathrm{n}=$ 25 ) and Caesarean Section (SC, $n=480$ ). The summary regarding the group of factors, factors, data structure and description of factors is presented in Table 1 .

The actual injuries were divided according to standard classification of particular injuries.

Patients with labia majora and labia minora tears and patients with periurethral tears (labia minora laessio/majora/laessio paraurethralis, LL) were divided into two groups, one consisted of patients with injuries $(n=128)$ and the second one consisted of patients without injuries in the area $(n=1249)$.

Patients with ruptura perinei (RP) were divided into 4 groups. Patients without RP $(n=1096)$, patients with 1st degree of ruptura perinei including those with fissura perinei (RP1, $n=201$ ), patients with 2nd degree of ruptura perinei $(\mathrm{RP} 2, \mathrm{n}=51)$ and patients with 3rd degree of ruptura perinei (RP3, $n=29$ ).
Another monitored injury was vagina walls tearing (ruptura parietis vaginae $-\mathrm{RPV}$ ). The patients were divided into two groups - patient with RPV $(n=221)$ and patients without RPV $(n=1156)$.

Monitored injuries also included the ruptura cervicis (RC). Patients were divided into 5 groups based on the location of RC - the group of patients with RC in the area No. 3 (RC3, $n=14$ ), patients with RC in the area No. 9 (RC9, $n=13$ ), patients with bilateral RC (RC3 + 9, $\mathrm{n}=16)$, patients with RC elsewhere (RCI, $n=33)$ and patients without RC (RC0, $n=1301)$.

The research also studied the amount of simultaneous multiple injuries in one patient occurring during one childbirth. With regard to injuries patients were divided into the following groups - no injury ( $\mathrm{n}=857)$, patients with one injury $(\mathrm{n}=350)$, patients with two injuries $(n=139)$, patients with three injuries $(n=20)$, patients with four injuries ( $\mathrm{n}=7$ ) and patients with five injuries (n $=4$ ) occurring simultaneously, while the group of patients with no injuries also featured patients who delivered their child via Caesarean Section $(n=480)$. An overview of the injuries distribution is presented in the Table 2.

Statistical methods were chosen with regard to the nature of data categories. Statistical calculations used the program " $R$ Project” (2). The statistical evaluation used Chi-square and Fisher's test. 
In the first step we determined the $p$ - value of the factors between each group by using statistical tests. We were able to detect statistically significant dependences which are elaborated on in the steps to come.

For the highest level of significance we determined the degree of correlation using a Phi coefficient, contingency coefficient and Cramer's V. The more the value of the coefficient approaches zero, the greater the degree of independence of A and B values.

For the highest values determining the degree of correlation we have drawn up a cohort study.

\section{Results}

When examining the impact of the labor induced with prostaglandin on the occurrence and extent of birth-canal injuries, the most significant $\mathrm{p}$ value was found for ruptura parietis vaginae ( $\mathrm{p}$ $=0.01378)$ and ruptura cervicis $(p=0.0358)$. A closer examination of the relationship between ruptura cervicis and induced labor did not reveal statistically significant $\mathrm{p}$ values $(\mathrm{RC} 3 \mathrm{p}=0.6069$, RC9 $p=0.09706, \mathrm{RC} 3+9 \mathrm{p}=0.81, \mathrm{RCI} \mathrm{p}=0.148$ ).

With regard to induced labor and its relationship with the type of delivery the most significant p values were discovered for the correlation of induced labor and Caesarean Section $\left(p=6.17 \times 10^{-9}\right)$ when compared to the correlation between induced labor and nonoperational vaginal delivery $\left(\mathrm{p}=5.569 \times 10^{-7}\right)$. P values of operative vaginal delivery using vacuum extractor $(p=0.6162)$ and operative forceps-assisted vaginal delivery $(p=0.3683$ ) showed no statistical differences.

By studying the impact of various types of delivery on birthcanal injuries we have found that the $p$ value relationship regarding the above shows a statistical dependence $\left(\mathrm{p}=2.2 \times 10^{-16}\right)$.

$P$ value of the relationship between non-operative vaginal deliveries vs. 1st degree ruptura perinei $\left(p=2.26 \times 10^{-16}\right)$ was more significant than $\mathrm{P}$ value of non-operative vaginal delivery vs. 3rd degree ruptura perinei $(p=0.583)$. The $p$ value of operative vaginal deliveries in relation to 1 st degree ruptura perinei $(p=0.08$ for OVDV and $\mathrm{p}=0.51$ for OFVD ) did not show any statistical significance. However, p - value of operative vaginal deliveries in relation to 3rd degree ruptura perinei $(\mathrm{p}=0.03554$ for OVDV and $\mathrm{p}$ $=0.005534$ for OFVD) was statistically significant. The correlation degree regarding non-operational deliveries and 1st degree ruptura perinei (Phi-constant $=0.313$, contingency coefficient $=0.298$, Cramer's V $=0.313$ ) showed a moderate dependence. A cohort study showed the occurrence of 1st degree ruptura perinei during 23.5 of vaginal delivery cases. The risk ratio reached 25.52 (Tab. 3).

$\mathrm{P}$ values of the relationship between individual types of delivery and ruptura parietis vaginae showed the most significant values in the case of operative vaginal deliveries using vacuum extractor vs. ruptura parietis vaginae $\left(\mathrm{p}=2.2 \times 10^{-16}\right)$. Slightly less significant $\mathrm{p}$ values were found in the case of non-operative vaginal deliveries vs. ruptura parietis vaginae $\left(p=8.189 \times 10^{-13}\right)$. $\mathrm{P}$ values regarding the relationship between the type of delivery and ruptura cervicis were the most significant in the case of nonoperative vaginal delivery vs. ruptura cervicis formed elsewhere $\left(\mathrm{p}=1.633 \times 10^{-5}\right)$.

The research of the impact of the type of delivery on birth-canal injuries found more significant p values in case of the group "38th week” undergoing Caesarean Section ( $p=0.0003487$ ) compared with non-operative vaginal delivery ( $p=0.007453)$, operative vaginal deliveries using vacuum extractor $(\mathrm{p}=0.2645)$ and operative forceps-assisted vaginal delivery $(p=0.3474)$. In the group „39 $39^{\text {th }}$ week" the most significant $p$ value was again found in the case of Caesarean Section ( $p=0.02471$ ) compared with non-operative vaginal delivery ( $p=0.0755)$, operative vaginal deliveries using vacuum extractor $(p=0.2279)$ and operative forceps-assisted vaginal delivery $(p=1)$. In the case of the group "40th week" no $p$ value showed statistical significance ( $p=0.2677$ to 1 ). The group "41st week +" showed the most significant $p$ values in relation to the Caesarean Section $\left(p=9.786 \times 10^{-5}\right)$ compared with non-operative vaginal delivery $(\mathrm{p}=0.002252)$, operative vaginal deliveries using vacuum extractor $(p=0.08376)$ and operative forceps-assisted vaginal delivery $(\mathrm{p}=0.3525)$.

Individual $p$ values regarding the relationship between the gestation period vs. extent of injuries pointed to significant $p$ values in the case of „41st week +“vs no injury ( $\mathrm{p}=0.0008441)$, „41st week +“vs 1 injury ( $\left.\mathrm{p}=3.414 \times 10^{-16}\right)$, “41st week +” vs 2 injuries ( $\mathrm{p}=$ $\left.4.523 \times 10^{-13}\right)$, “41st week +” vs 3 injuries $(p=0.006299)$. Significant p values were also found in cases of " 38 th week" vs 1 injury $(p=0.0009941)$ and “38th week” vs 2 injuries $(p=0.0003164)$.

\section{Discussion}

Meharunnissa Kashkeli et al in their study from 2010 focused on the determination of the frequency, type and complications of birth-canal injuries during delivery. Of the total set of 9216 patients 467 (5.06 \%) had a birth-canal injury. The most common birthcanal injury in the case of primiparas was a tear in the vaginal wall (16 cases, $25.39 \%$ ) and perineal tears (12 cases, $19.04 \%$ ). In case of multiparas (196 in total, $41.97 \%$ ) the most common birth-canal injury was a cervical tear (26.53\%). In case of grand - multiparas the most common birth-canal injury was a cervical tear (208 cases, $44.4 \%$ ) and uterine rupture (77 cases, $37.01 \%$ ) The most frequent post-partum complications included haemorrhage (75.37 \%), hypovolemic shock (47.10 \%) and infection (33.83 \%) (4).

\section{Tab. 3. Cohort study NOVD vs RP.}

\begin{tabular}{|c|c|c|c|c|c|}
\hline$\frac{\mathrm{RP1}}{\mathrm{NSVD}}$ & Yes & No & In total & $\begin{array}{c}\text { Incidence } \\
\text { (Inc risk *) }\end{array}$ & Odds \\
\hline Yes & 196 & 638 & 834 & 23.501 & 0.30721 \\
\hline No & 5 & 538 & 543 & 0.921 & 0.00929 \\
\hline In total & 201 & 1176 & 1377 & 14.597 & 0.17092 \\
\hline
\end{tabular}

RP1 - 1st degree ruptura perieni 1, NOVD - Non-operative delivery per vaginam 
511-514

Using mathematical - statistical methods we proved that labor induced with prostaglandin has a positive impact on the occurrence and extent of birth-canal injuries in terms of increasing their presence. Labor induced with prostaglandin also affects the type of injury in terms of increased risk of vaginal wall tear and cervical tear.

We proved that labor induced with prostaglandin is associated with a higher risk of Cesarean section delivery. This finding is also confirmed by Boulvain et al in their retrospective cohort study from 2001 that included 7430 women. The author states: "Induction of labor was found to be associated with a higher risk of Caesarean section [RR = 2.4, 95\% CI 1.8, 3.4]“ (5)

Seyb ST, et al. in 1999 carried out a cohort study of 1561 pregnant women. These were divided into 3 groups: spontaneous delivery, programmed delivery, induced labor due to medical indications. $7.8 \%$ of women having a spontaneous delivery had a Cesarean section, while women with programmed induced labor with PG had a Cesarean delivery rate of $17.5 \%$ (adjusted odds ratio [OR] 1.89; 95\% confidence interval [CI] 1.12, 3.18) and women undergoing medically indicated labor induction had a 17.7 \% Cesarean delivery rate (OR 1.69; 95\% CI 1.13, 2.54). (6)

We found that the type of delivery is also a risk factor for birthcanal injuries. Non-operative vaginal delivery was a risk factor for 1st degree ruptura perinei. In our study the incidence of 1st degree ruptura perinei was 23.5 cases out of 100 cases. In the case of the operational vaginal birth (forceps, vacuum extractor), however, the 1st degree ruptura perinei risk changed into 3rd degree risk. In addition, the use of vacuum extractor also increases the risk of a tear of vagina walls. From this perspective, we consider the use of vacuum extractor as the most risky factor in relation to the injury of the birth canal. Zwinger states that operative vaginal deliveries (forceps delivery or vacuumextraction) cause a higher frequency of birth-related traumas. (7)

Poen in their retrospective case-control study from 1997 compared 120 women who have experienced 3rd degree of ruputra perinei with 702 cases without ruputra perinei with respect to possible risk factors. In the conclusion they found that the risk factors for 3rd degree of ruputra perinei included forceps delivery, induced labor, epidural anesthesia and nulliparity (8).

We pointed out that the gestation period influences the type of delivery. The delivery in 38th week or in/ after 41st week poses an increased risk of Cesarean section delivery.

With regard to statistical tests we have proven the impact of gestation period on the extent of birth-canal injuries. Greater extent of injuries occurred in case of deliveries before/ in 38th week and in/ after 41st week. Conversely, patients delivering their child in 40th week had a statistically proven relation to zero and one type of birth-related injuries.

\section{Conclusion}

Our study, involving 1377 patients, has shown that labor induced with prostaglandins increases the occurrence and extent of birth-related injuries. Labor induced with prostaglandins also affects the type of delivery, particularly increasing the risk of Cesarean section. We have proven the influence of the delivery type on birth-canal injuries. Non-operative vaginal delivery is a risk factor for 1st grade ruptura perinei, operative vaginal birth using a vacuum extractor and forceps are risk factors for 3rd grade ruptura perinei. Operative vaginal deliveries using a vacuum extractor also increase the risk of vagina walls tear. We have also proven the impact of gestation period on the occurrence and extent of birth-canal injuries. Deliveries before 38th gestation week or in / after 41st week accounted for an increased risk of Cesarean section delivery. These groups of patients recorded a greater range of birth-canal injuries.

\section{References}

1. Bil' S. Prostaglandíny v pôrodníckej praxi. Slov Gynek Pôrod 2008; 15 (2): 71-76.

\section{2. https://www.r-project.org/}

3. Markechová D, Stehlíková B, Tirpáková A. Štatistické metódy a ich aplikácie. Nitra: UKF Nitra, 2011, 537 s.

4. Kashkeli M, Baloch S, Baloch AS. Obstetrical trauma to the genital tract following vaginal delivery. J Coll Phys Surg (Pakistan) 2012; 22 (2): 95-97.

5. Boulvain M, Marcoux S, Bureau M, Fortier M, Fraser W. Risks of induction of labour in uncomplicated term pregnancies. Paediatr Perinat Epidemiol 2001; 15 (2): 131-138.

6. Seyb ST, Berka RJ, Socol ML, Dooley SL. Risk of cesarean delivery with elective induction of labor at term in nulliparous women. Obstet Gynecol 1999; 94 (4): 600-607.

7. Zwinger A. Porodnictví. Praha: Galén, 2004, 513 s.

8. Poen AC, Felt-Bersma RJF, Dekker GA, Devillé W, Cuesta MA, Meuwissen SGM. Third degree obstetric perineal tears: risk factors and the preventive role of mediolateral episiotomy. Intern J Obstet Gynaecol 1997; 104: 563-566.

9. Dosedla E et al. Indukcia pôrodu. Gynekol Prax 2011; 9 (3): 120-125.

Received April 9, 2016. Accepted April 28, 2016. 